\title{
Electrochemical Detection of Glucose by Using Glucose Oxidase Modified Platinum Electrode
}

\author{
Iram Yasmin \\ School of Chemistry, Northeast Normal University \\ NabilahAl-Ansi \\ School of Chemistry, Northeast Normal University \\ Bin Qi* \\ Associate Professor, School of Chemistry, Northeast Normal University
}

\begin{abstract}
In this research, the cysteamine self-assembled monolayers (SAM), is required to modify surface of pt electrode. Now, by using the method of chemical binding and electrochemical deposition the surface of platinum electrode was modified by glucose oxidase enzyme. Platinum plate $(0.5 \mathrm{~cm} \times 0.5 \mathrm{~cm})$, platinum rod and silver or silver chloride electrodes act as working, auxiliary and reference electrodes, individually. The manufactured of pt. /GOD electrode described by electrochemical impedance spectroscopy (EIS). The glucose oxidase modified platinum electrode was used for detection of glucose by Amperometric measurement. The amperometric response of the sensor was observed under some factors i.e. $\mathrm{pH}$, Concentration, Temperature and applied potential. Detection of glucose can be taken by oxidation of enzymatically formed $\mathrm{H} 2 \mathrm{O} 2$ at $0.8 \mathrm{~V}$. A high current response was occur at $\mathrm{pH} 7.5$ and potential $+0.8 \mathrm{~V}$. Enzyme is stronger at high temperature because of micro environment but at $28{ }^{\circ} \mathrm{C}$ biosensor show good response and this is working temperature. The stability of the enzyme electrode was also deliberated. Moreover, the performance of the glucose oxidase enzyme was reserved about $59.9 \%$ after a time of 15 days. These factors show pt/GOD electrode is good or successful biosensor for detection of glucose.

Graphical abstract:
\end{abstract}

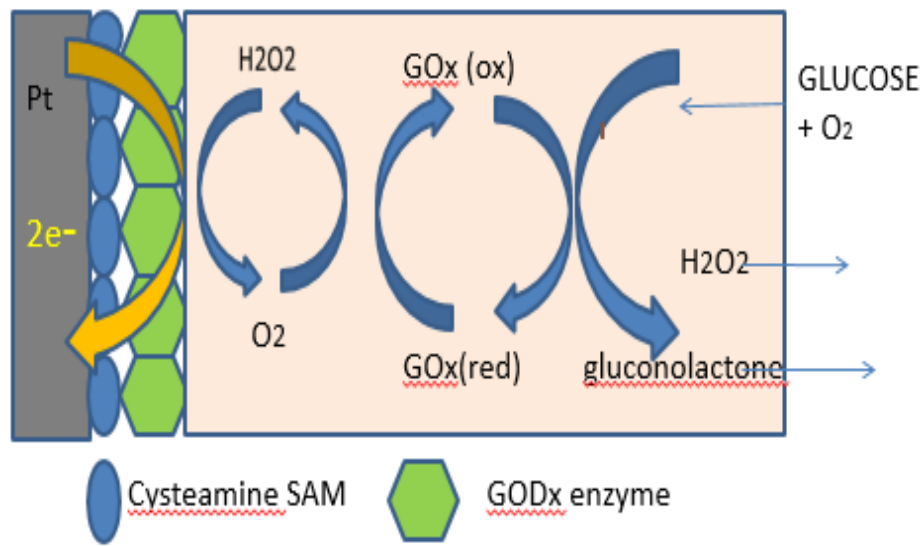

Index Terms - Biosensor, Cysteamine self-assembled, Glucose oxidase, Glucose, Immobilization, DOI: $10.7176 / \mathrm{CMR} / 11-4-03$

Publication date: April $30^{\text {th }} 2019$

\section{INTRODUCTION}

Glucose is a bio-particle, a carbohydrate that is well-known and have very significant role in the benefit of humanity. The progress of glucose oxidase modified sensors in research area is due to its significance, as in diabetes mellitus condition these biosensors are commonly used also have main role in nutritional science and ecological checking and progression productions, etc. [1-5]. The important leading polymers polyaniline, polypyrene was used for immobilization of enzymes. [6-8]. Electrochemical technique based on glucose oxidase has been well known among all other evolved techniques for determination of glucose [9-12]. The amperometric glucose biosensors commonly used for the determination of glucose. The purpose of bio- composites with sensors has numerous benefits, e.g. comfort of use, speed and detection of analyte and the formation of analytical techniques founded on modified biosensors [13].

Due to its uses as bio-sensing compound, glucose have unique features such as: (i) Electrochemical oxidation of monomer is an easy way to modify sensor electrode, (ii) mechanism of wideness and (iii) 
conductivity [14] developing an enzyme electrode. Glucose oxidase is very important and commonly used enzyme, because of its high binding, greater stability and comparatively greater sensitivity. Glucose oxidize in the presence of oxygen to produce hydrogen peroxide, which can be identified by mean of working electrodes [e.g., platinum ( $\mathrm{Pt}$ ) at potentials $+0.8 \mathrm{~V}$ (vs. silver/silver chloride). Glucose oxidase can usually promote this process of oxidation. Their extensive uses and benefits in diverse fields, reaching from detection of gas, optics to electronics, and particularly bio medical science. In the occurrence of oxygen, glucose oxidize to gluconolactone by glucose oxidase enzyme whereas coenzyme flavinadenindinucleotide (FAD) is reduced to FADH2. O2 work as an acceptor of electron for FADH2 in a normal enzymatic reaction and deoxidizes FADH2 to flavinadenindinucleotide, however molecular oxygen is reduced to hydrogen peroxide. Fig.1 The hydrogen peroxide is then identified by electrochemical study, permitting the purpose of the resultant concentration of glucose solution (15).

$\underset{\text { Hydrogen peroxide }}{\mathrm{O} 2+\text { Glucose }} \stackrel{\mathrm{H}_{2} \mathrm{O}_{2}}{\longrightarrow \text { gluconolactone }} \quad \begin{gathered}\mathrm{Eq} 1 \\ \longrightarrow\end{gathered} 2 \mathrm{H}^{+}+\mathrm{O}_{2}+2 \mathrm{e}$

In biosensor formation, GOD immobilization effect was deliberated on the platinum surface by using (SAMs) of cysteamine. In count, the working of the glucose oxidase modified biosensors, containing the response current, sensitivity of enzyme and stability, was described.

\section{EXPERIMENTAL DESIGN \\ REAGENTS}

Glucose oxidase enzyme (, EC1.1.3.4. from Aspergil us Niger, $1 \mathrm{mg} / \mathrm{mL}$ ) and glucose was taken from Sigma. The glucose stock solution was freshly arranged in phosphate buffer (PBS) $(\mathrm{pH}=7.5)$ and left at $6^{\circ} \mathrm{C}$ overnight to permit the equilibration of the anomers. By using Na2HPO4 and KH2PO4 $0.01 \mathrm{M}$ phosphate buffer (PBS) solution was organized. Alumina powder and Cysteamine were achieved from Sigma. Supportive electrolyte used are KH2PO4 + Na2HPO4 was taken from sigma. 0.1 M phosphate buffer solution was used to clean the electrode and kept at $6^{\circ} \mathrm{C}$. By using distilled water all solutions were formed.

\section{INSTRUMENTATION}

Epsilon EC electrochemical analyzer with a three-electrode system, Platinum electrode was act as working electrode. A silver/silver chloride electrode and a Platinum rod were act as reference and auxiliary electrode, separately for electrochemical measurement. The Orion Model $720 \mathrm{~A} \mathrm{pH} /$ ion meter was used for measurement of $\mathrm{pH}$ values of the buffer solutions.

\section{Measurements of Electrochemical response of enzyme sensor}

Electrochemical response of glucose was measured in PBS $(0.1 \mathrm{M} \mathrm{pH} 7.5)$ solution. By sensing the $\mathrm{H} 2 \mathrm{O} 2$ oxidation current at $0.8 \mathrm{~V}$ the Performance of electrode, Sensitivity, $\mathrm{pH}$, storage stability and temperature were measured. After the stable value of current to the three-electrode cell, glucose solution was added using a micropipette and it was agitated. Then the resultant current difference was measured. From different concentrations of glucose, we study the sensitivity, storage stability as well as effects of $\mathrm{pH}$ and temperature were measured.

\section{RESULTS AND DISCUSSION}

In this research Glucose oxidase enzyme was used to develop a sensitive electrochemical enzyme electrode. The factors effecting to the working of the modified biosensor were studied.

\section{PREPARATION OF PT/GODx ELECTRODE}

Other than modification procedure of electrode, the polishing of platinum electrode was occurred with Alumina powder and cleaned with deionize water. Oxygen plasma (power of $200 \mathrm{~W}, 400 \mathrm{~s}$, oxygen flow of $100 \mathrm{sccm}$ ) was used to dry or clean the surface of platinum electrode to remove the impurities. After the process of polishing the platinum electrode was dissolved in acetone solution for 6 hours which contain $4 \mathrm{mM}$ cysteamine. Then electrode was washed with acetone and dry under the flow of oxygen plasma. Then electrochemical measurements were taken till the good voltammogram characteristics of electrode was obtained. Finally, cysteamine self- assembled monolayer was formed on platinum electrode to bind the enzyme on the modified platinum surface. Then modified platinum electrode was soaked in glucose oxidase solution which contain $0.1 \mathrm{M}$ of phosphate buffer (PBS, $\mathrm{pH}$ 7.5). Behind this investigation of immobilization of enzyme glucose oxidase was electrochemically deposited onto the Platinum Electrode surface. (figure 1). After formation, cysteamine SAM modified pt/GODx electrodes were cleaned carefully in deionized water and desiccated in cool air and then use for successive description. We absorbed the pt/GODx electrode into 0.1M PBS solution when the electrode was used for glucose detection and kept at $6{ }^{\circ} \mathrm{C}$ until used. 


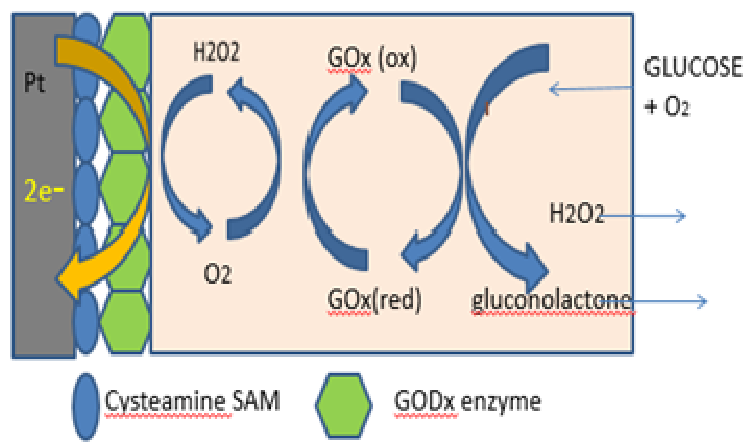

Fig.1. Preparation of pt. /GODx electrode

\section{CHARACTERIZATION OF PLATINUM ELECTRODE}

Electrochemical measurement was taken in glucose solution in $0.1 \mathrm{mM}$ PBS buffer and different concentrations of glucose $(10 \mathrm{mM}, 20 \mathrm{mM}, 30 \mathrm{mM}, 40 \mathrm{mM}, 50 \mathrm{mM}, 60 \mathrm{mM})$ was taken to study the response current of modified platinum electrode. shown in (Fig 2). We initiate that as we increase the concentration of glucose in $0.1 \mathrm{mM}$ PBS the response current of the glucose oxidase modified platinum electrode properly altered at $0.2-1 \mathrm{~V}$. The increase in peak currents occur immediately as the increase in concentration of glucose occur, and a linear plot is obtained upto $0.8 \mathrm{~V}$ and above $0.8 \mathrm{~V}$ the decrease in response current was observed just because of high concentration of oxygen in the solution. That study shows that at even very low concentration we detect glucose and biosensor have high sensitivity at $0.8 \mathrm{~V}$. All of the elements in solution react with the Platinum /GODx electrode but do not react with each other .
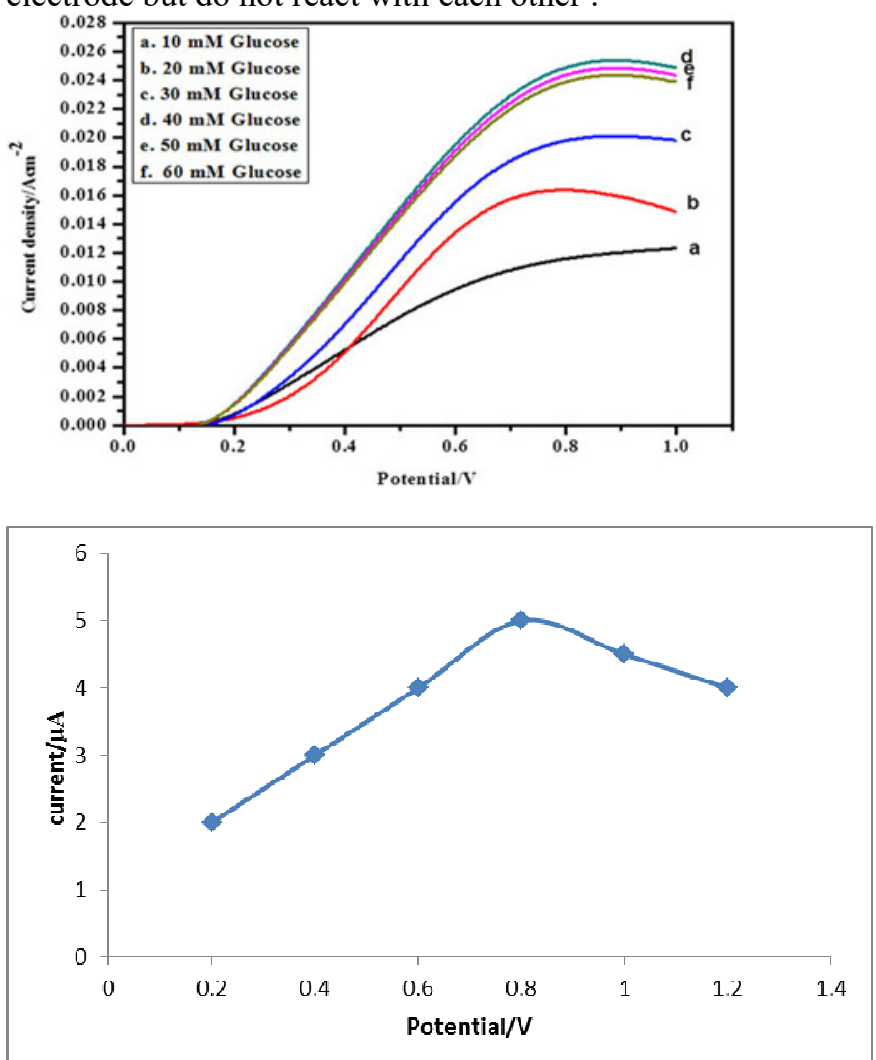

Fig.2. The current response of a modified glucose biosensor at different concentration of glucose. linear plot is obtained up to potential $0.8 \mathrm{~V}$

\section{EFFECT OF PH ON ENZYME ELECTRODE}

The glucose oxidase modified platinum electrode show high sensitivity to hydrogen peroxide and it was examined at five different $\mathrm{pH}$ values $(4,5.5,7.5,9.5$, and 10.5). Existing values that were attained were drawn against concentration of glucose. The effect of $\mathrm{pH}$ value on the working of the modified platinum electrode is 
very significant because the act of immobilize glucose oxidase depends on $\mathrm{pH}$ values [16]. In this learning, requirement of a modified platinum electrode on $\mathrm{pH}$ values was calculated over the range from 4 to 10.5 . The glucose oxidase electrode showed lower or greater current response to glucose, when the $\mathrm{pH}$ of the buffer was lower or higher. And best response current was detected at a $\mathrm{pH}$ value of 7.5 figure 3 .

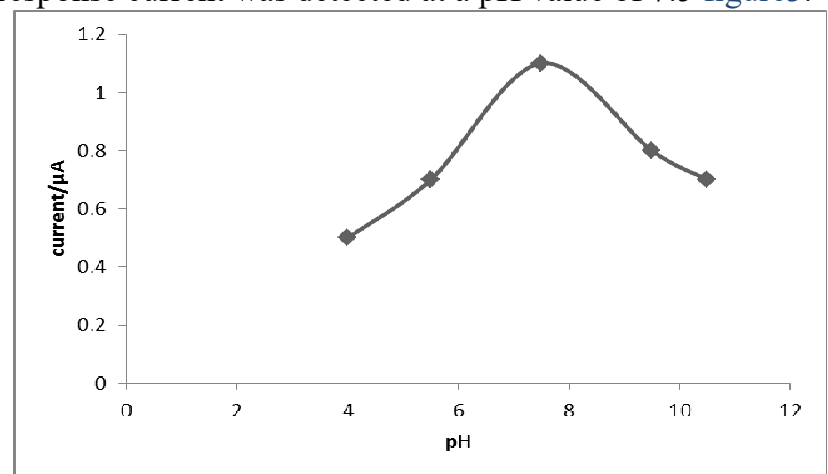

Fig.3. .Effect of $\mathrm{pH}$ on the response current of the electrode to $\mathrm{H} 2 \mathrm{O} 2$.

\section{VOLTAMMOGRAMS OF BIOSENSOR}

This kind of modified biosensors show a good response current of glucose was studied and is shown in fig.4.The effects show that detector(working) electrode (Edet) have greater electron transfer competences. We detected that the redox current become high predictably when concentration of glucose increased and glucose oxidized to gluconolactone at a high potential than $0.6 \mathrm{~V}$ and it increased to $0.8 \mathrm{~V}$. Redox current become stable when the applied voltage was higher than $0.8 \mathrm{~V}$. The curve of glucose oxidase modified Pt electrode has a stable current response, and the practical applied potential was $0.8 \mathrm{~V}$ because of the effect of concentration of oxygen in electrochemical solution figure 5. As the concentration of glucose increased we found that the redox current also increased linearly. However, the glucose oxidase platinum electrode modified with the monolayer of cysteamine show large response current to glucose detection in $(0.1 \mathrm{Mm}$ PBS) solution. The electrolyte used develop a microenvironment that increase the enzyme activity and response current of electrode also increased. The high response currents of glucose to electrode was observed at applied potential of $0.8 \mathrm{~V}$.

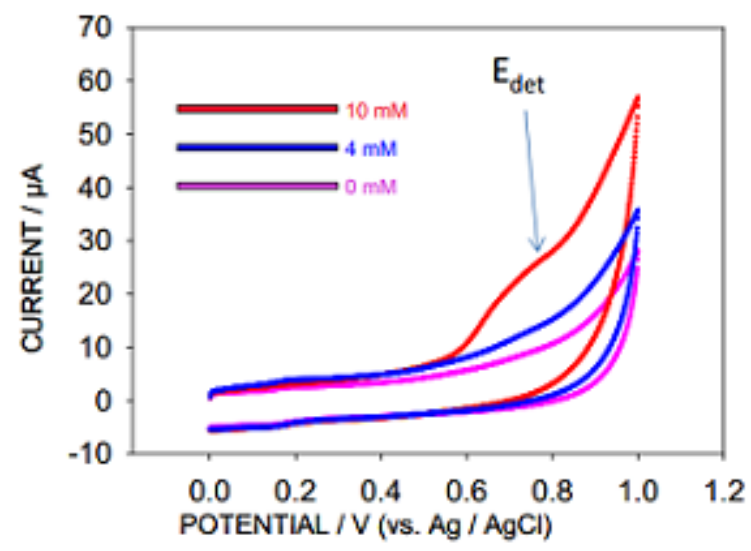

Fig.4. Volta gram of glucose at applied potential

\section{EFFECT OF TEMPERATURE ON PT/GODX SENSOR}

Temperature has very important influence on activity of enzyme and it is significant to examine the response of the biosensor at different temperature. The effect of temperature on the response of glucose enzyme platinum electrode was complete between $20^{\circ} \mathrm{C}$ and $80{ }^{\circ} \mathrm{C}$ at $\mathrm{pH}(7.5 \mathrm{PBS})$ using same $1 \mathrm{mM}$ concentration of glucose (Figure 6). At $50{ }^{\circ} \mathrm{C}$ biosensor have a good response for glucose detection and enzyme is stronger at $50{ }^{\circ} \mathrm{C}$ due to its microenvironment. Moreover, temperature between $20-28^{\circ} \mathrm{C}$ is considered as working temperature. 


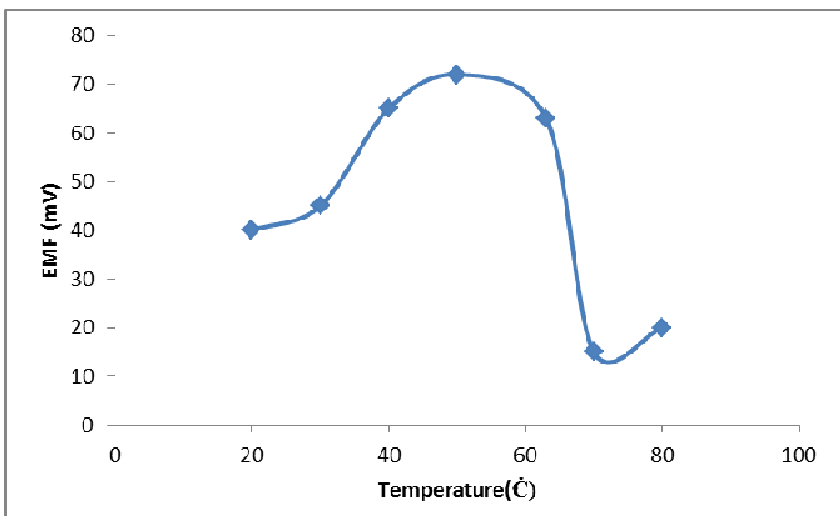

Fig 5.The temperatures effect on the activity of the enzyme sensor (at $\mathrm{pH} 7.5,1 \mathrm{Mm}$ ) glucose at $0.8 \mathrm{~V}$ working potential).

\section{Stability of the glucose biosensor}

The glucose oxidase modified Platinum electrode was organized under the same situations designated above for sensing glucose. The biosensor is stored in phosphate buffer for few days, glucose sensor responses is high at the start but decreased in the first 12 days gradually, and after 15 days the modified electrode show constant activity around about $59.9 \%$, it shows better stability of the glucose oxidase enzyme immobilized on the modified surfaces of platinum electrode. Figure 7. indicated that after a long experiment current response decreased and effected by leaking enzyme due to free links of glucose oxidase on the surface of platinum electrode.

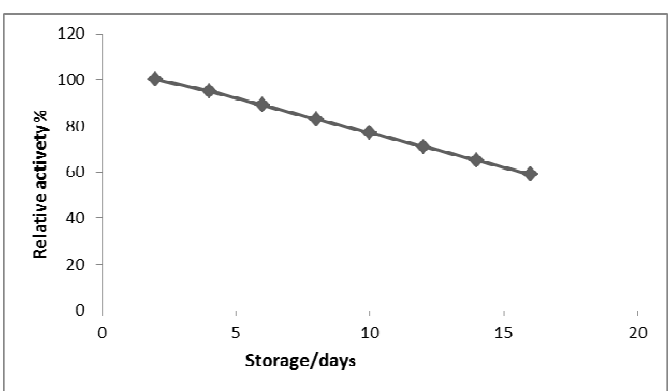

Fig.6. Stability of the modified pt electrode phosphate buffer(pH,7.5) at a $0.8 \mathrm{~V}$

\section{Conclusion}

The immobilization of glucose oxidase enzyme is studied by binding chemical groups on Platinum electrode surfaces, and the response current of the Platinum electrode is highly reliant on the process of modification of surface. The large response current was attained when the Platinum electrode was modified with the cysteamine for immobilization of glucose oxidase enzyme. The experimental effects obviously presented that the subsequent enzyme sensor showed good activity in the detection of glucose. Detection of glucose can be taken by oxidation of enzymatically formed hydrogen peroxide at $0.8 \mathrm{~V}$. A high current response was occur at $\mathrm{pH} 7.5$ and applied potential $+0.8 \mathrm{~V}$ (versus silver/silver chloride). It was observed that glucose oxidase modified platinum electrode was sensitive and have longer stability were establish to be better. Besides, the stability and catalyst activity of the glucose oxidase were reserved at about $59.9 \%$ after a time period of 15 days.

\section{References}

[1] Choi, H. N., Kim, M. A., \& Lee, W. Y. (2005). Amperometric glucose biosensor based on sol-gel-derived metal oxide/Nafion composite films. Analytica Chimica Acta, 537(1-2), 179-187.

[2] Liu, H., Qian, J., Liu, Y., Yu, T., \& Deng, J. (1996). Immobilization of glucose oxidase in the composite membrane of regenerated silk fibroin and poly (vinyl alcohol): application to an amperometric glucose sensor. Bioelectrochemistry and bioenergetics, 39(2), 303-308.

[3] Tong, H. D., Chen, S., van der Wiel, W. G., Carlen, E. T., \& van den Berg, A. (2009). Novel top-down wafer-scale fabrication of single crystal silicon nanowires. Nano letters, 9(3), 1015-1022.

[4] Le, T. T. T., Tran, P. D., Pham, X. T., Tong, D. H., \& Dang, M. C. (2010). Glucose oxidase immobilization on different modified surfaces of platinum nanowire for application in glucose detection. Advances in Natural Sciences: Nanoscience and Nanotechnology, 1(3), 035004.

[5] Zhu, J., Zhu, Z., Lai, Z., Wang, R., Guo, X., Wu, X., ... \& Chen, Z. (2002). Planar amperometric glucose 
sensor based on glucose oxidase immobilized by chitosan film on Prussian blue layer. Sensors, 2(4), $127-$ 136.

[6] Bidan, G. (1992). Electroconducting conjugated polymers: new sensitive matrices to build up chemical or electrochemical sensors. A review. Sensors and Actuators B: Chemical, 6(1-3), 45-56.

[7] Arslan, F., Ustabaş, S., \& Arslan, H. (2011). An amperometric biosensor for glucose determination prepared from glucose oxidase immobilized in polyaniline-polyvinylsulfonate film. Sensors, 11(8), 8152-8163.

[8] Bartlett, P. N., \& Cooper, J. M. (1993). A review of the immobilization of enzymes in electropolymerized films. Journal of Electroanalytical Chemistry, 362(1-2), 1-12.

[9] D.D. Cunningham, J.A. Stenken, In Vivo Glucose Sensing, Wiley, USA, 2009.

[10] C. Chen, Q. Xie, D. Yang, H. Xiao, Y. Fu, Y. Tan, S. Yao, Recent advances in electrochemical glucose biosensors: a review, RSC Adv. 3 (2013) 4473-4491.

[11] J. Wang, Electrochemical glucose biosensors, Chem. Rev. 108 (2008) 814-825.

[12] A. Heller, B. Feldman, Electrochemical glucose sensors and their applications in diabetes management, Chem. Rev. 108 (2008) 2482-2505.

[13] Wang, H. J., Zhou, C. M., Peng, F., \& Yu, H. (2007). Glucose biosensor based on platinum nanoparticles supported sulfonated-carbon nanotubes modified glassy carbon electrode. Int. J. Electrochem. Sci, 2, 508516.

[14]Borole, D. D., Kapadi, U. R., Mahulikar, P. P., \& Hundiwale, D. G. (2004). Glucose oxidase electrodes of polyaniline, poly (o-toluidine) and their copolymer as a biosensor: a comparative study. Polymers for Advanced Technologies, 15(6), 306-312.

[15] Yoo, E. H., \& Lee, S. Y. (2010). Glucose biosensors: an overview of use in clinical practice. Sensors, 10(5), 4558-4576.

[16]Luo, X. L., Xu, J. J., Zhao, W., \& Chen, H. Y. (2004). Glucose biosensor based on ENFET doped with SiO2 nanoparticless. Sensors and Actuators B: Chemical, 97(2-3), 249-255. 